\title{
Cognitive stimulation therapy improved cognition and quality of life in dementia
}

Spector A, Thorgrimsen L, Woods B, et al. Efficacy of an evidence-based cognitive stimulation therapy programme for people with dementia: randomised controlled trial Br J Psychiatry 2003;183:248-54.

$Q$ In people with dementia, does cognitive stimulation therapy (CST) improve cognition and quality of life?

\section{METHODS}

$\square$

Design: randomised controlled trial

Allocation: concealed.

Blinding: blinded (outcome assessor)

Follow up period: 7 weeks.

Setting: 5 day centres and 18 residential homes (with $\geqslant 15$ people in each) in the UK.

Patients: 201 people (mean age $85 y, 79 \%$ women) who met DSM-IV criteria for dementia, scored 10-24 on the Mini-Menta State Examination (MMSE), were able to communicate laccording the Clifton Assessment Procedures for the ElderlyBehaviour Rating Scale), had sufficient vision and hearing to participate and use material in a group, and did not have majo physical illness or disability (including learning disability).

D Interventions: CST $(n=115)$ : fourteen 45 minute sessions twice week for 7 weeks. The programme used the concepts of reality orientation and cognitive stimulation and included the topics of money, word games, the present day, and famous faces. "Usual activities" $(n=86)$ : in most settings, this consisted of doing nothing.

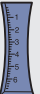

Outcomes: cognition (MMSE), quality of life (Quality of LifeAlzheimer's Disease Scale), communication (Holden Communication Scale), behaviour (Clifton Assessment Procedures for the Elderly-Behaviour Rating Scale), global functioning (Clinical Dementia Rating Scale), depression (Cornell Scale for Depression in Dementia), and anxiety (Rating Anxiety in Dementia)

$\square \square$

Patient follow up: $83 \%$. Sciences, University College London, London, UK. m.orrell@ucl.ac.uk Sources of funding: NHS London Regional Office Research and Development Programme, and Barking, Havering and Brentwood Community NHS Trusts.

\section{MAIN RESULTS}

Analysis was by intention to treat. More patients in the CST group than in the usual care group had $\geqslant 4$ points improvement on the Alzheimer's Disease Assessment Scale-Cognition \{relative benefit increase 131\%, 95\% CI 27 to 330; number needed to treat 6, CI 4 to $19\}^{*}$. Cognition and quality of life were improved in the CST group but deteriorated in the usual activities group (table). The groups did not differ for any other outcome (table).

\section{CONCLUSION}

In people with dementia, cognitive stimulation therapy improved cognition and quality of life.

*RBI, NNT, and CI calculated from data in article.

A modified version of this abstract appears in Evidence-Based Medicine.

See commentary on next page.

Cognitive stimulation $v$ usual activities in dementia at 7 weeks*

\begin{tabular}{lccc}
\hline \multicolumn{3}{c}{ Mean change score } & \\
\cline { 2 - 3 } Outcomes & $\begin{array}{l}\text { Cognitive } \\
\text { stimulation }\end{array}$ & Activities & Mean score difference (Cl) \\
\hline MMSE & 0.9 & -0.4 & $1.14(0.57$ to 2.27$)$ \\
ADAS-Cog & 1.9 & -0.3 & $2.37(0.64$ to 4.09$)$ \\
QoL-AD & 1.3 & -0.8 & $1.64(0.09$ to 3.18$)$ \\
Holden & 0.2 & -3.2 & $2.3(-0.45$ to 4.15$) \dagger$ \\
CAPE-BRS & -0.2 & -0.7 & $0.40(-0.9$ to 1.69$) \dagger$ \\
RAID & -0.5 & -0.7 & $-1.30(-3.48$ to 0.87$) \dagger$ \\
Cornell & 0 & -0.5 & $0.12-1.56$ to 1.31$) \dagger$
\end{tabular}

${ }^{*}$ ADAS-Cog = Alzheimer's Disease Assessment Scale-Cognition; CAPE-BRS = Clifton Assessment Procedures for the Elderly-Behaviour Rating Scale; Cornell = Cornell Scale for Depression in Dementia; Holden = Holden Communication Scale; QoL-AD = Quality of LifeAlzheimer's Disease; RAID = Rating Anxiety in Dementia. Other abbreviations defined in glossary. †Not significant 